\title{
Rancang Bangun Customer Relationship Management Penjualan Barang Elektronik Pada PT Primakarsa Niaga Indonesia Berbasis Website
}

\author{
Design and Build Customer Relationship Management Sales of Electronic Goods at \\ PT Prakarsa Niaga Indonesia Based on Website
}

\author{
Agung Wijaya ${ }^{1}$, Mulyati ${ }^{2}$ \\ ${ }^{1,2}$ Program Studi Sistem Informasi, Universitas Multi Data Palembang \\ e-mail: ${ }^{* 1}$ agungwijaya616@gmail.com, ${ }^{2}$ muliati@mdp.ac.id
}

\begin{abstract}
Abstrak
PT Primakarsa Niaga Indonesia merupakan perusahaan yang bergerak dibidang distributor elektronik. Tujuan dibangun Customer Relationship Management pada PT Primakarsa Niaga Indonesia ini adalah mempermudah pelanggan luar kota dalam memesan produk. Selain itu sistem dapat menampilkan kriteria produk secara detail, dapat menampilkan produk barang yang paling diminati, dan meningkatkan kepuasan kepada pelanggan dengan adanya sistem cashback pada saat transaksi, sehingga pelanggan dapat melakukan pembelian kembali menggunakan cashback tersebut. Sehingga dengan tercapainya tujuan tersebut dapat meningkatkan penjualan barang elektronik pada PT Primakarsa Niaga Indonesia. Metode yang digunakan dalam pembangunan sistem informasi ini adalah RUP (Rational Unified Process) dimana metode ini mengarah kepada pengembangan berorientasi objek. RUP (Rational Unified Process) adalah pendekatan pengembangan perangkat lunak yang dilakukan berulang-ulang, fokus pada arsitektur, lebih diarahkan berdasarkan penggunaan kasus (use case driven). Hasil dari penelitian ini adalah sebuah website yang dapat memberikan pelayanan kepada pelanggan dengan menggunakan sistem yang terintegrasi serta mempermudah proses penjualan barang elektronik.
\end{abstract}

Kata kunci: Customer Relationship Management, RUP, Website.

\section{Abstract}

PT Primakarsa Niaga Indonesia is a company engaged in electronics distributors. The purpose of developing Customer Relationship Management at PT Primakarsa Niaga Indonesia is to make it easier for out-of-town customers to order products. In addition, the system can display product criteria in detail, can display the most desirable products, and increase customer satisfaction with the cashback system at the time of transaction, so that customers can make purchases again using the cashback. So that the achievement of these goals can increase sales of electronic goods at PT Primakarsa Niaga Indonesia. The method used in the development of this information system is RUP (Rational Unified Process) where this method leads to object-oriented development. RUP (Rational Unified Process) is an iterative approach to software development, focusing on architecture, more directed towards use cases (use case driven). The result of this research is a website that can provide services to customers using an integrated system and simplify the process of selling electronic goods..

Keywords: Customer Relationship Management, RUP, Website. 


\section{PENDAHULUAN}

\subsection{Latar Belakang}

Seiring dengan perkembangan zaman, perusahaan-perusahaan yang ada mulai mengalami perkembangan. Hal ini dialami oleh perusahaan, baik perusahaan skala kecil maupun skala besar. Perkembangan teknologi informasi pun juga berkembang dengan sangat cepat dan pesat.

CRM membutuhkan penyusunan seluruh strategi bisnis, termasuk semua penjualan dan saluran komunikasi, untuk pemeliharaan sistematis hubungan pelanggan. Fokusnya adalah berorentasi pada produk, layanan, pelanggan serta nilai yang tinggi dikaitkan dengan kegunaan pelayanan. Tujuan dari semua kegiatan CRM adalah untuk memperoleh dan meningkatkan nilai pelanggan (yaitu, kepuasan pelanggan dan loyalitas pelanggan) serta profitabilitas pelanggan selama seluruh waktu hubungan pelanggan (customer lifetime value).

Bisnis yang dulunya dilakukan secara manual ataupun tradisional, kini mulai bergeser ke otomatisasi. Transaski yang dulunya memerlukan waktu berhari-hari, sekarang dapat diproses dalam waktu yang cepat. Hal ini menjadi tantangan baru dalam dunia bisnis.

PT Primakarsa Niaga Indonesia merupakan perusahaan yang bergerak dibidang distributor elektronik, seperti Midea, Samsung, Steko, RSA\&GEA, Toshiba, Sharp. Beralamat di Jalan Kol. H. Burlian Km. 9 (Samping JM Sukarme) Palembang. Sistem yang berjalan pada perusahaan PT Primakarsa Niaga Indonesia yaitu perusahaan membuka toko retail pada tanggal 21 Oktober 2019, dengan nama Burlian Jaya Elektronik, dengan dibukanya toko retail ini diharapkan dapat mendorong peningkatan pelanggan dan peningkatan penjualan. Seiring berjalannya waktu muncul permasalahan baru pada PT Primakarsa Niaga Indonesia yaitu dimana perusahaan sulit untuk menjangkau pelanggan dari luar kota, pelanggan kesulitan dalam mengetahui informasi tentang produk apa saja yang ada serta promosi yang diberikan oleh perusahaan, masih belum adanya kriteria produk barang yang paling diminati oleh pelanggan, belum adanya sistem cashback dan point. Salah satu strategi untuk mengatasi permasalahan yang terjadi adalah merubah paradigma bisnis perusahaan menjadi perusahaan yang berorientasi kepada pelanggan.

Berdasarkan penelitian sebelumnya yang dilakukan oleh[1] permasalahan pada PT Musi Lestari Indo Makmur antara lain pencarian informasi mengenai masa berakhirnya penyewaan tempat membutuhkan waktu cukup lama, sulitnya calon penyewa untuk mendapatkan informasi mengenai exhibition, dan adanya keterlambatan pembayaran sewa, selanjutnya penelitian yang di lakukan oleh [2] pada Salon Muslimah dan SPA Desi Khadijah permasalahan yang dihadapi yaitu pelanggan terlalu lama menunggu layanan jasa perawatan dikarenakan belum adanya informasi status terapis sehingga terdapat keluhan pelanggan, tidak ada pengklasifikasian dalam pencatatan data regular dan data member, dan pelanggan tidak dapat memilih terapis yang diinginkan. Penelitian selanjutnya dilakukan oleh [3] pada PT. Jasa Angkasa Semesta merupakan perusahaan di bidang jasa dengan bisnis utama di bidang ground handling, selain itu juga mempunyai produk yang antara lain : Ground Services, Cargo Services, Lounge dan Airport Special Assistance. Airport Special Assistance atau disingkat ASA yaitu merupakan layanan yang menawarkan bantuan bandara kelas premium. Penumpang bisa memperoleh kenyamanan dengan layanan terpadu ASA seperti asisten pribadi, porter, mobil mewah, in-ride entertainment, lounge dan bantuan imigrasi. Dalam hal reservasi dapat melaui e-mail dengan mengirimkan data-data seperti nama lengkap, nomor dan jam penerbangan dan scan paspor. Permasalahan yang dihadapi untuk pencataan data operational dilakukan secara manual menggunakan Ms. Excel, selain itu Airport Special Assistance belum mengelola data pelanggan dengan baik, sehingga belum menjalin hubungan yang lebih kuat dengan pelanggan. 
Sehingga untuk mengatasi permasalahan yang dihadapi oleh karena itu Customer Relationship Management (CRM) merupakan salah satu metode yang dapat digunakan oleh perusahaan PT Primakarsa Niaga Indonesia untuk mengembangkan strategi bisnis yang berpusat atau berorentasi kepada pelanggan, juga berfokus merawat hubungan pelanggan, membangun dan mengelola hubungan antara perusahaan dan pelanggan.

Berdasarkan permasalahan yang terjadi pada perusahaan PT Primakarsa Niaga Indonesia, maka diberikan solusi "Rancang Bangun Customer Relationship Management (CRM) Penjualan Barang Elektronik Pada PT Primakarsa Niaga Indonesia Berbasis Website”.

\subsection{Permasalahan}

Adapun permasalahan yang akan penulis angkat untuk penelitian di PT Primakarsa Niaga Indonesia adalah sebagai berikut:

1. Perusahaan sulit menjangkau pelanggan luar kota dan mempertahankan pelanggan lama. Pelanggan sulit mengetahui infomasi tentang produk dan informasi promosi yang diberikan oleh perusahaan.

2. Belum adanya laporan mengenai produk yang paling diminatin oleh pelanggan berdasarkan transaksi pelanggan sehingga perusahaan belum dapat menentukan promosi untuk pelanggan.

3. Pelanggan belum tertarik dalam memesan produk dikarenakan perusahaan belum menerapkan sistem voucher, point dan cashback.

\subsection{Tujuan}

Adapun tujuan yang ingin dicapai dari sistem yang dibangun pada PT Primakarsa Niaga Indonesia adalah sebagai berikut:

1. Mempermudah pelanggan luar kota dalam memesan produk.

2. Aplikasi CRM ini dapat menampilkan kriteria produk secara detail.

3. Aplikasi dapat menampilkan produk barang yang paling diminati.

4. Meningkatkan kepuasan kepada pelanggan dengan adanya sistem cashback pada saat transaksi, sehingga pelanggan dapat melakukan pembelian kembali menggunakan cashback tersebut.

\subsection{Manfaat}

Adapun manfaat dari sistem yang dibangun pada PT Primakarsa Niaga Indonesia adalah sebagai berikut:

1. Perusahaan mendapatkan pelanggan dari luar kota.

2. Perusahaan dapat memberikan informasi cashback dan promosi kepada pelanggan.

3. Perusahaan dapat mengetahui produk barang yang diminati oleh pelanggan, sehingga perusahaan dapat membuat strategi berikutnya.

4. Perusahaan lebih mudah menentukan cashback dan point berdasarkan jumlah transaksi pelanggan.

\subsection{Sistem Informasi}

Sistem informasi adalah suatu sistem di dalam suatu organisasi yang mempertemukan kebutuhan pengolahan transaksi harian yang mendukung operasi organisasi yang bersifat manajerial dengan kegiatan strategi dari suatu organisasi untuk dapat menyediakan laporanlaporan yang diperlukan oleh pihak luar tertentu. [4].

\subsection{Customer Relationship Management}

Definisi CRM (Customer Relationship Management) menurut [5] sebagai proses holistic dalam mengidentifikasi, menarik, mendiferensiasiakan, dan mempertahankan pelanggan dengan jalan mengintegrasikan rantai pasokan perusahaan guna menciptakan customer value pada setiap langkah dalam proses penciptaan nilai. 


\subsection{Karakteristik CRM}

Tipe-tipe dan karakteristik dari CRM [6] dibagi menjadi empat, yaitu sebagai berikut:

\section{Strategi}

Strategi CRM adalah strategi pemasaran yang dilakukan berdasarkan dari kebutuhan pelanggan yang menguntungkan.

2. Operasional

Operasional CRM yang berfokus pada proses menghadapi para pelanggan seperti pemasaran, penjualan serta layanan pelanggan.

3. Analitis

Analitis CRM berfokus pada menganalisis yang berhubungan dengan pelanggan untuk kepentingan dalam pembuatan strategi perusahaan.

4. Kolaborasi

Kolaborasi CRM yaitu berbagai departemen dari organisasi seperti front office, sales, housekeeping dan marketing saling berbagi informasi serta hasil dari interaksi yang mereka dapat tentang pelanggan yang bertujuan untuk mengoptimalkan perusahaan, menjaga kepuasan pelanggan serta loyalitas pelanggan.

\subsection{RUP (Rational Unified Process)}

RUP (Rational Unified Process) adalah pendekatan pengembangan perangkat lunak yang dilakukan berulang-ulang (iterative), fokus pada arsitektur (architecture-centric), lebih diarahkan berdasarkan penggunaan kasus (use case driven). RUP merupakan proses rekayasa perangkat lunak dengan pendifinisian yang baik (well defined) dan penstrukturan yang baik (well structured) [7]. Gambar 1 berikut adalah proses iteratif pada RUP.

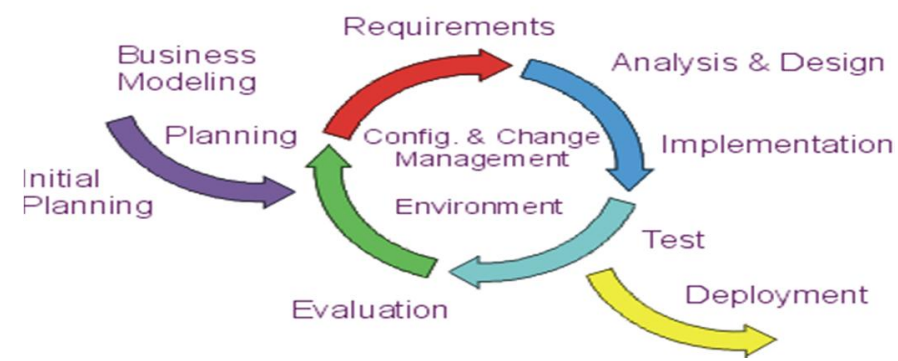

Gambar 1. Proses Pengulangan / Iteratif pada RUP

\section{$1.9 M y S Q L$}

"MySQL atau dibaca "My Sekuel" dengan adalah suatu RDBMS (Relational Database Management System) yaitu aplikasi sistem yang mejalankan fungsi pengolahan data" [9].

MySQL adalah salah satu aplikasi DBMS yang sudah banyak oleh para pemogram aplikasi web. Contoh DBMS lainnya adalah: PostgreSQL (freeware), SQL Server, MS Access dari Microsoft, DB2 dari IBM, Oracle dan Oracle Corp, Dbase, FoxPro, dsb [10].

\subsection{Hypertext Preprocessor (PHP)}

PHP adalah pemograman interpreter yaitu proses penerjemahan baris kode sumber menjadi kode mesin yang dimenegerti komputer secara langsung pada saat baris kode dijalankan [9].

\subsection{Java Script}

Java Script adalah suatu bahasa pemograman yang dikembangkan untuk dapat berjalan pada web browser [9]. 


\subsection{Cascading Style Sheet (CSS)}

Cascading Style Sheet (CSS) adalah dikembangkan untuk menata gaya pengaturan halaman web, terdiri dari selector properti dan nilai seperti halnya $H T M L$ atau PHP dan bahasa pemograman lainnya [9].

\subsection{Analisis PIECES}

Analisis PIECES merupakan analisis yang melihat sistem dari Performance/Data, Economic, Control/Security, Efficiency, dan Service [8].

- Kehandalan (Performance)

Kehandalan suatu sistem merupakan variable pertama dari PIECES dimana mempunyai peran penting untuk melihat sejauh mana dan seberapa handalkah suatu sistem informasi dalam berproses untuk menghasilkan tujuan yang diinginkan.

Variable ini dapat digunakan sebagai acuan atau pedoman dalam menevaluasi sistem dengan memperhatikan 2 komponen berikut:

a. Kemampuan suatu sistem dalam mengerjakan sejumlah perintah/penugasan dalam periode waktu yang telah ditentukan, dengan baik dan tanpa hambatan (errors).

b. Cepat atau lambatnya kemampuan sistem dalam merespon suatu perintah/program pembatalan ataupun permintaan terhadap suatu transaksi.

Hal ini dapat disesuaikan juga dengan kapasitas komputer yang digunakan dalam pemrosesan. Bila komponen dalam komputer untuk memenuhi suatu requirement sistem tinggi, makan seharusnya response time yang diperlukan cepat.

- Informasi (Information)

Informasi merupakan komoditas krusial bagi pengguna akhir. Evaluasi terhadap kemampuan sistem informasi dalam menghasilkan informasi yang bermanfaat perlu dilakukan untuk menyikapi peluang dan menangani masalah yang muncul. Dalam hal ini meningkatkan kualitas informasi tidak dengan menambah jumlah informasi, karena terlalu banyak informasi malah akan menimbulkan masalah baru.

\section{- Ekonomi (Economic)}

Alasan ekonomi barangkali merupakan motivasi paling umum bagi suatu proyek. Pijakan bagi kebanyakan manajer adalah biaya atau rupiah. Persoalan ekonomis dan peluang berkaitan dengan masalah biaya.

- Kontrol (Control)

Tugas-tugas bisnis perlu dimonitor dan dibetulkan jika ditemukan kinerja yang dibawah standar. Kontrol dipasang untuk meningkatkan kinerja sistem, mencegah, atau mendeteksi kesalahan sistem, menjamin keamanan data, dan persyaratan.

- Efisiensi (Efficiency)

Efisiensi menyangkut bagaimana menghasilkan output sebanyak-banyaknya dengan input yang sekecil mungkin. Berikut adalah suatu indikasi bahwa suatu sistem dapat dikatakan tidak efisien:

1. Banyak waktu yang terbuang pada aktivitas sumber daya manusia, mesin, atau komputer.

2. Data dimasukkan atau disalin secara berlebihan.

3. Data diproses secara berlebihan.

4. Informasi dihasilkan secara berlebihan.

5. Usaha yang dibutuhkan untuk tugas-tugas terlalu berlebihan.

6. Material yang dibutuhkan untuk tugas-tugas terlalu berlebihan.

- Layanan (Services)

Berikut adalah kriteria penilaian dimana kualitas suatu sistem bisa dikatakan buruk: 
1. Sistem menghasilkan produk yang tidak akurat.

2. Sistem menghasilkan produk yang tidak konsisten.

3. Sistem menghasilkan produk yang tidak dipercaya.

4. Sistem tidak mudah dipelajari.

5. Sistem tidak mudah digunakan.

6. Sistem canggung untuk digunakan.

7. Sistem tidak fleksibel

\section{METODE PENELITIAN}

Metode penenlitian yang digunakan dalam rancang bangun customer relationship management yaitu Rational Unified Process (RUP). RUP mempunyai beberapa tahapan sebagai berikut:

1. Inception (Permulaan)

Pada tahap ini lebih kepada memodelkan proses bisnis yang dibutuhkan serta mendefinisikan kebutuhan sistem yang akan dibuat. Pada tahap ini penulis melakukan obseravasi, wawancara, dan pengumpulan dokumen terkait dengan observasi yang dilakukan.

\section{Elaboration (Perencanaan)}

Pada tahap ini lebih memfokuskan pada perencanaan arsitektur sistem. Tahap ini meliputi pembuatan Use Case, PIECES, Activity Diagram, Sequence Diagram, dan Class Diagram

\section{Construction (Konstruksi)}

Pada tahap ini lebih memfokuskan pada pengembangan dan fitur-fitur sistem. Tahap ini lebih pada implementasi dan penguji sistem yang fokus pada implementasi perangkat lunak pada kode program. Penulis akan mulai membangun sistem berbasis web dengan menggunakan PHP, HTML dan MySQL sebagai basis datanya.

\section{Transition (Transisi)}

Pada tahap ini lebih kepada instalasi sistem agar bisa digunakan serta dimengerti oleh pengguna. Tahap ini memberikan produk perangkat lunak dimana menjadi syarat batas kemampuan operasional awal.

\section{HASIL DAN PEMBAHASAN}

\subsection{Analisis Permasalahan.}

Adapun permasalahan yang akan diidentifikasi dengan menggunakan kerangka PIECES yaitu pada Tabel 1 berikut:

Tabel 1. Analisis PIECES

\begin{tabular}{|c|l|}
\hline PIECES & \multicolumn{1}{|c|}{ Keterangan } \\
\hline Performance & $\begin{array}{l}\text { Membutuhkan waktu yang cukup lama untuk mendapatkan } \\
\text { laporan penjualan berdasarkan pencarian riwayat transaksi } \\
\text { pelanggan. }\end{array}$ \\
\hline Information & $\begin{array}{l}\text { Perusahaan sulit memberikan informasi mengenai produk } \\
\text { dan promosi kepada pelanggan. }\end{array}$ \\
\hline Economic & $\begin{array}{l}\text { Terjadi pengeluaran biaya yang cukup besar untuk } \\
\text { melakukan promosi cetak spanduk dan brosur untuk } \\
\text { diberikan kepada pelanggan. }\end{array}$ \\
\hline
\end{tabular}




\begin{tabular}{|l|l|}
\hline Control & $\begin{array}{l}\text { Sering terjadi miskomunikasi antara pihak perusahaan dan } \\
\text { pelanggan mengenai alamat lokasi pelanggan. }\end{array}$ \\
\hline Efficiency & $\begin{array}{l}\text { Pihak perusahaan melakukan konfirmasi ulang nama } \\
\text { pelanggan, pesanan, dan alamat pelanggan sebelum } \\
\text { mencetak transaksi. }\end{array}$ \\
\hline Service & $\begin{array}{l}\text { Pelanggan kurang puas dengan pelayanan yang diberikan } \\
\text { perusahaan. }\end{array}$ \\
\hline
\end{tabular}

\subsection{Analisis Kebutuhan}

\subsubsection{Analisis Kebutuhan Fungsional}

Berikut Gambar 2 adalah use case diagram dari PT Primakarsa Niaga Indonesia

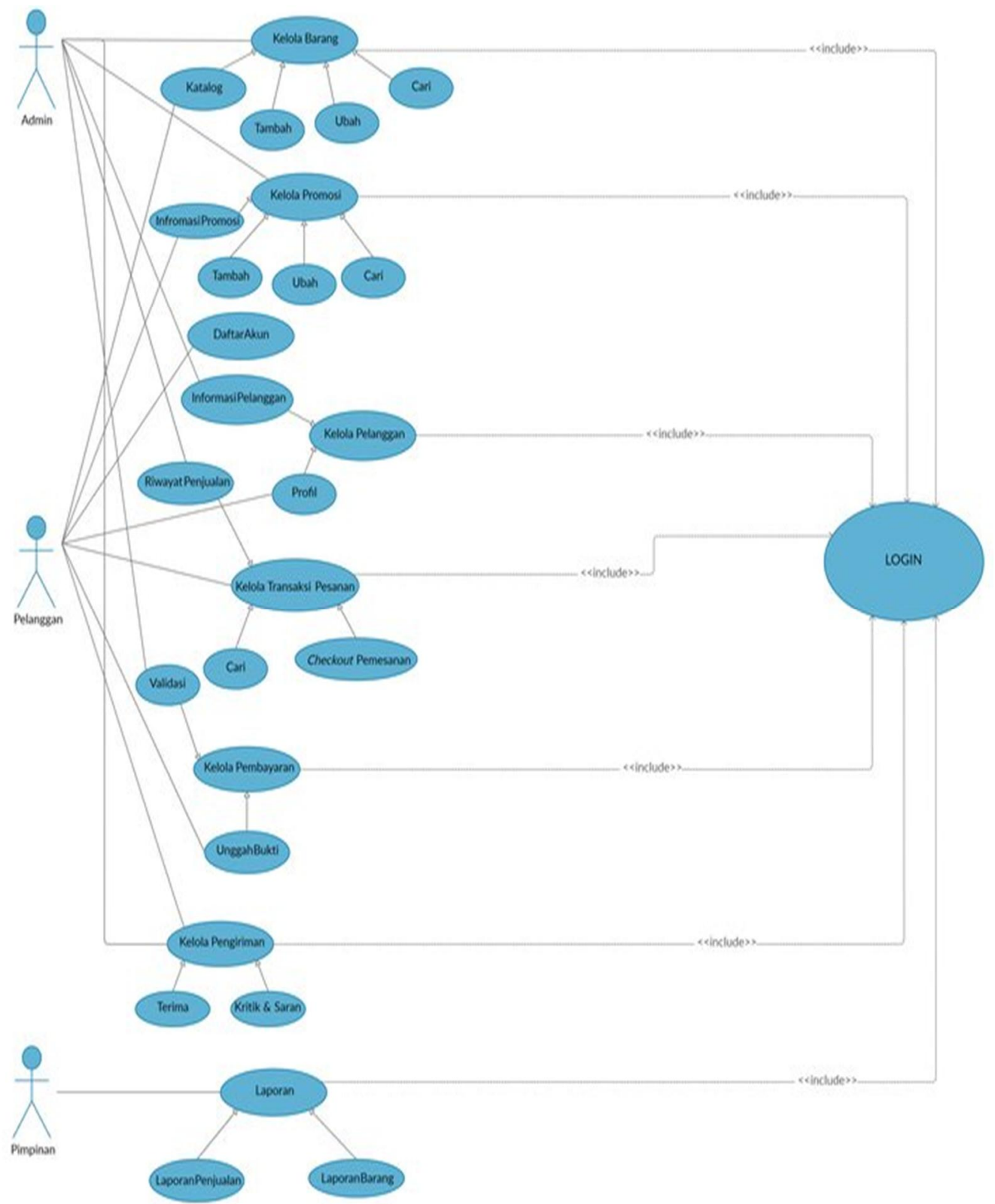

Gambar 2. Use Case Diagram 


\subsubsection{Kebutuhan Non Fungsional}

Kebutuhan non fungsional merupakan kebutuhan yang harus disediakan agar sistem dapat berjalan dan digunakan dengan baik. Berikut beberapa kebutuhan non fungsional yang harus disediakan :

1. Usability

Sistem yang dibangun mudah dimengerti serta memiliki tampilan yang baik.

2. Reability

Sistem yang berbasis website dan hanya bisa diakses oleh orang yang memang memiliki hak akses serta terdaftar.

3. Performance

Sistem yang dibangun diharapkan dapat memberikan kinerja yang lebih efisien dan efektif.

4. Information

Sistem yang dikembangkan dapat memberikan informasi yang dibutuhkan oleh Pengguna dan Pimpinan.

5. Security

Sistem yang dibangun memiliki keamanan. dalam hal mengakses data.

\subsection{Design Logis}

Design Logis merupakan bagian analisis persyaratan dari bisnis. Desain logis menentukan persyaratan untuk pengguna bisnis kedalam sebuah model sistem yang hanya menggambarkan persyaratan bisnis, bukan desain teknis ataupun implementasi persyaratan tersebut.

\subsubsection{Class Diagram}

Class diagram merupakan model statis yang menggambarkan struktur dan deskripsi class serta hubungan antara class, berikut gambar class diagram customer relationship management yang akan dibangun.

\subsubsection{Activity Diagram}

Gambar 3 ini menggambarkan aktivitas pengguna saat melakukan proses login untuk masuk ke dalam sistem, berikut activity diagram pada gambar 3 dibawah.

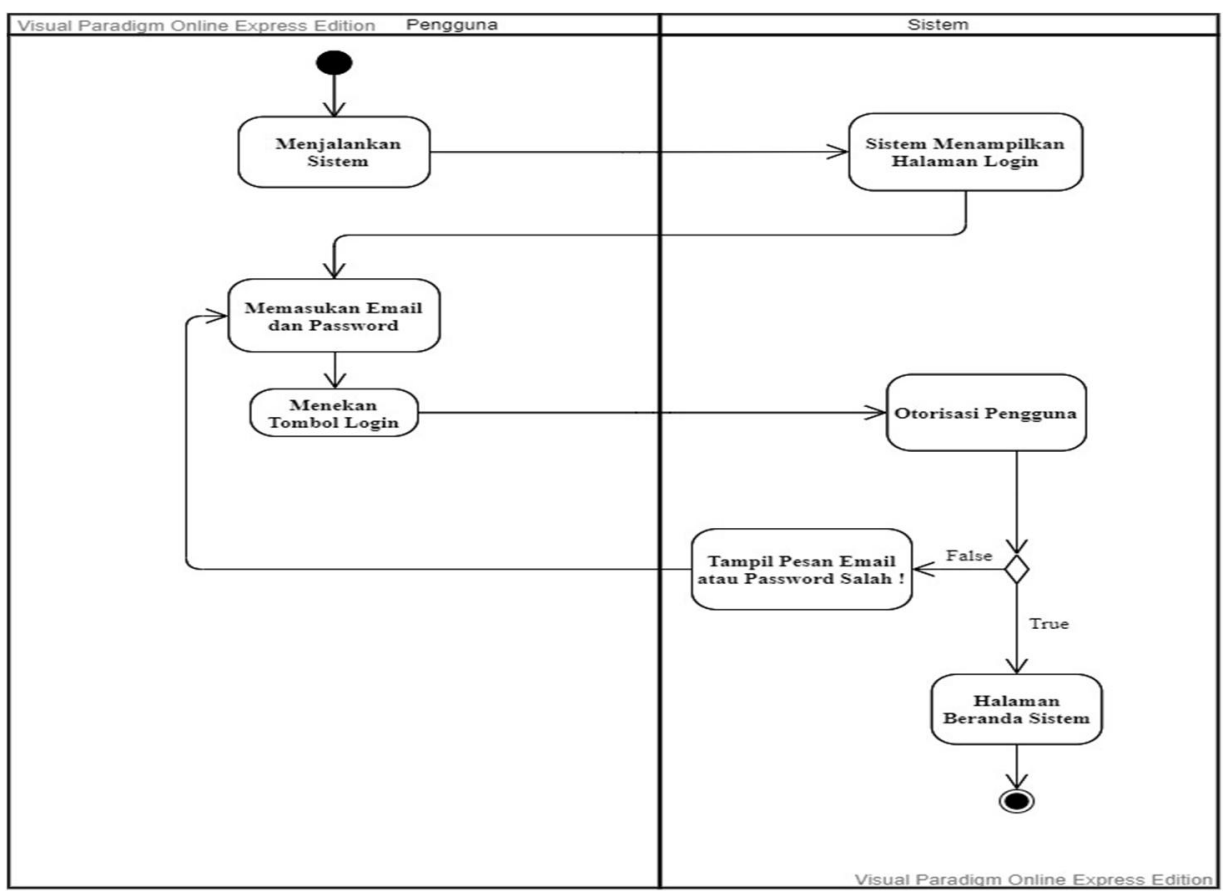

Gambar 3. Activity Diagram 


\subsubsection{Sequence Diagram}

Sequence diagram menggambarkan perilaku obyek pada usecase dengan menjelaskan lifetime dari obyek dan message yang dikirim dan diterima antar obyek.

Berikut Gambar 4 sequence diagram customer relationship management pada PT Primakarsa Niaga Indonesia:

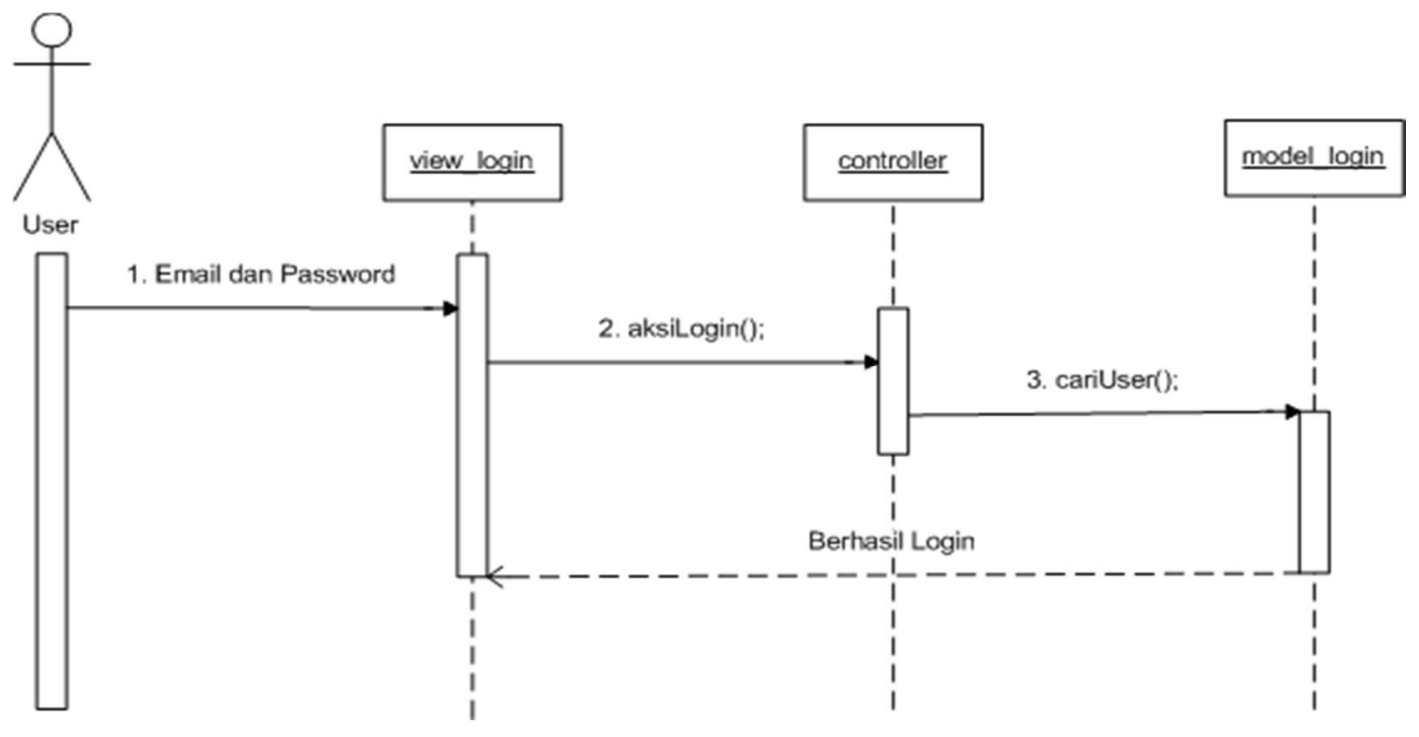

Gambar 4. Sequence Diagram Login

\subsection{Konstruksi dan Pengujian}

Tujuan dari konstruksi dan pengujian yaitu untuk membangun dan menguji sebuah sistem fungsional yang memenuhi persyaratan-persyaratan bisnis dan desain untuk mengimplementasikan antarmuka sistem dan sistem produksi yang telah ada.

\subsubsection{Tampilan Antarmuka Menu Utama}

Berikut Gambar 5 ini merupakan rancangan atau adalah tampilan Form Menu Utama

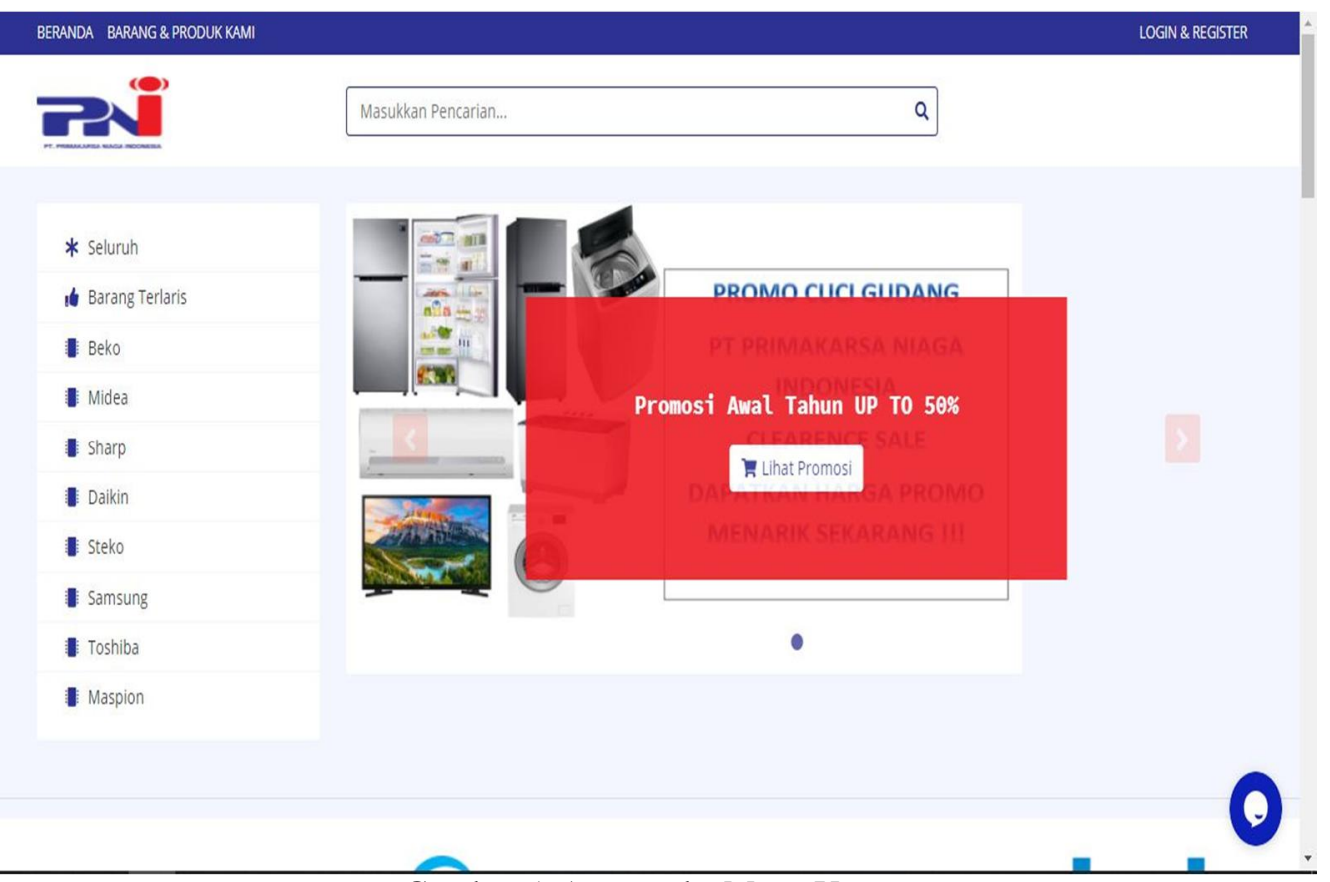

Gambar 5. Antarmuka Menu Utama 


\subsubsection{Tampilan Antarmuka Informasi Promosi \\ Berikut Gambar 6 ini merupakan rancangan atau adalah tampilan Form Informasi Promosi}

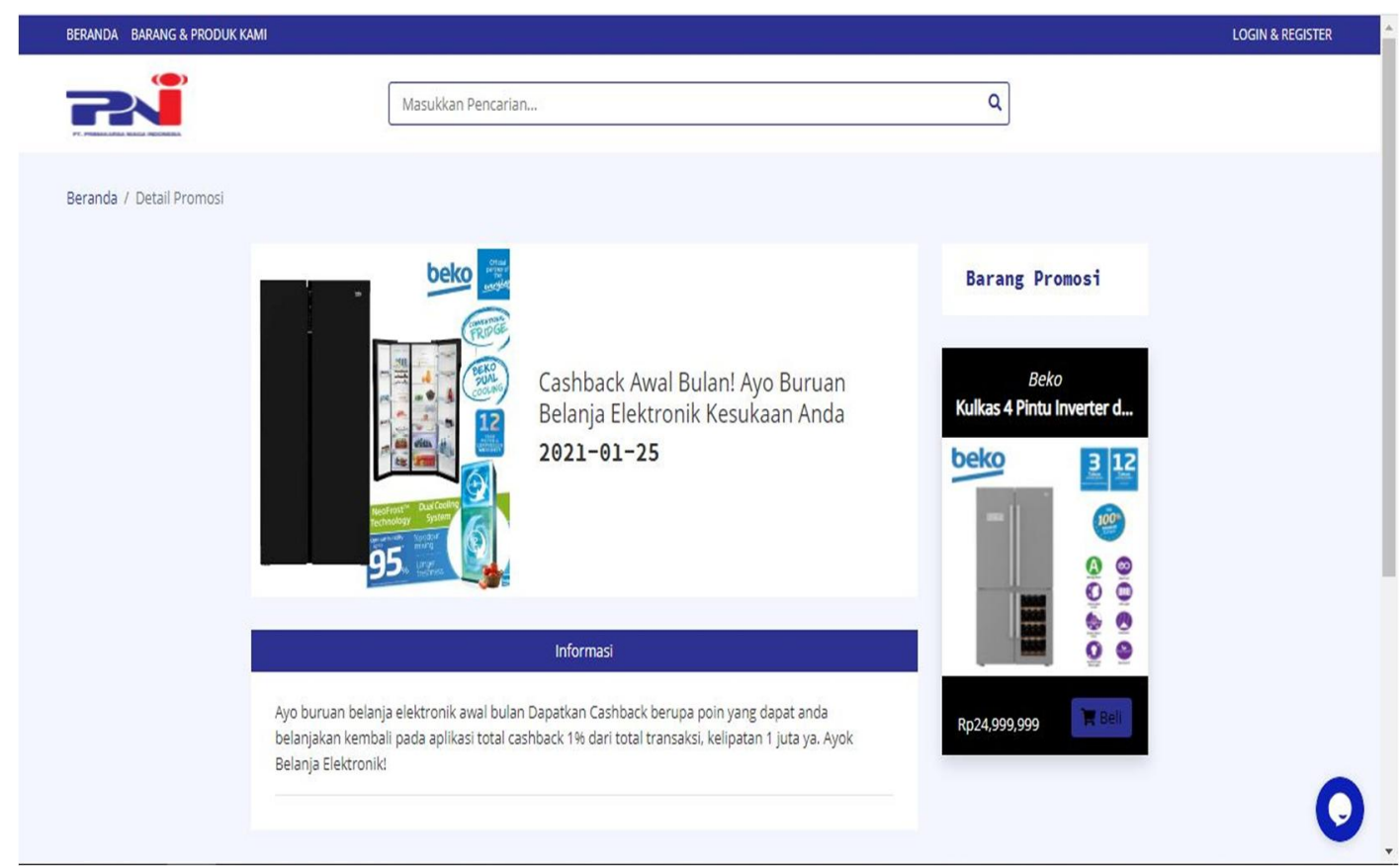

Gambar 6.Antarmuka Informasi Promosi

\subsubsection{Tampilan Antarmuka Tambah Barang}

Berikut Gambar 7 ini merupakan rancangan atau tampilan Form Tambah Barang

BERANDA INFORMASI PELANGGAN KELOLA PROMOSI KELOLA BARANG VALIDASI PEMBAYARAN RIWAYAT PENJUALAN

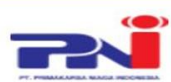

Beranda / Kelola Barang

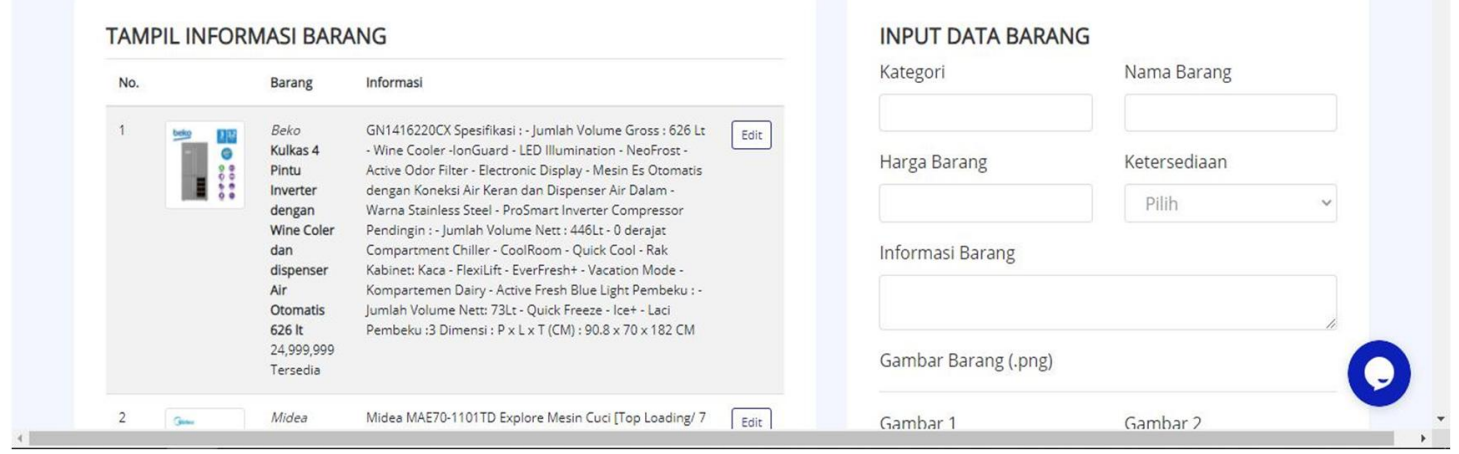

Gambar 7 Antarmuka Tambah Barang

\subsubsection{Tampilan Antarmuka Pemesanan Pelanggan}

Berikut Gambar 8 ini merupakan rancangan atau tampilan Form Pemesanan Pelanggan 


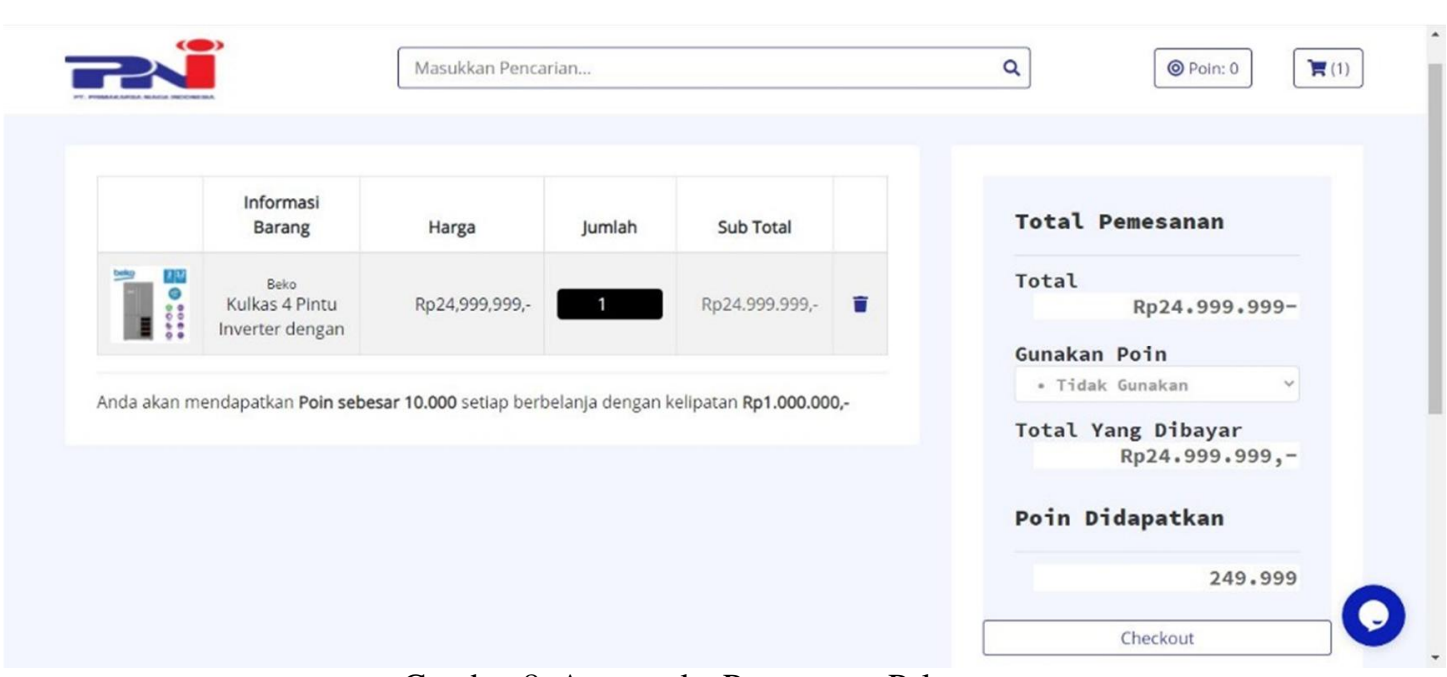

Gambar 8. Antarmuka Pemesanan Pelanggan

\section{KESIMPULAN DAN SARAN}

\subsection{Kesimpulan}

Hasil pengembangan sistem infromasi rancang bangun customer relationship management (CRM) penjualan barang elektronik pada PT Primakarsa Niaga Indonesia berbasis website, dapat membantu perusahaan dalam menjangkau pelanggan luar kota, pelanggan dapat mengetahui infromasi tentang produk dan promosi, perusahaan dapat menentukan barang yang paling diminati oleh pelanggan serta pelanggan dapat tertarik dengan adanya menu cashback dan point pada aplikasi.

\subsection{Saran}

Dalam merancang dan membangun sistem customer relationship management penulis menyadari masih adanya kekurangan pada sistem yang telah dibangun. Maka dari itu, penulis memberikan saran yang dapat digunakan dalam pengembangan customer relationship management dan menggunakan metode RUP (Rational United Process) pada PT Primakarsa Niaga Indonesia:

1. Sistem ini memerlukan pengembangan fitur yang telah ada untuk meningkatkan kinerja sistem agar sesuai dengan keinginan perusahaan

2. Perlu dilakukannya pemeliharaan dan peningkatan sistem secara berkala agar sistem dapat berkerja dengan maksimal.

3. Sistem ini dapat dikembangkan pada fitur bagian biaya pengiriman dan penambahan biaya untuk biaya asuransi.

4. Sistem ini bisa ditambahkan laporan dalam bentuk grafik.

\section{DAFTAR PUSTAKA}

[1] F. A. Chandra, F. Wijaya, M.H. Irfani, D. Pibriana. 2014, "Rancang Bangun Customer Relationship Management pada PT Musi Lestari Indo Makmur Palembang,” pp. 1-8. Seminar Perkembangan dan Hasil Penelitian Ilmu Komputer (SPHP-ILKOM).

[2] Loria dan D.I. Ricoida, 2012, "Sistem Informasi Manajemen Pelanggan pada Salon Muslimah dan Spa Desi Khadijah Palembang,” No. x, pp. 1-11. 
[3] N. Kumaladewi, S. Ratnawati, N. Hastiani. 2013, "Rancang Bangun Sistem Informasi Customer Relationship Management (CRM) Airport Special Assistance (Studi Kasus: PT Jasa Angkasa Semesta, Tbk.)”. Seminar Nasional Aplikasi Teknologi Informasi (SNATI).

[4] T. Sutabri, 2012, Analisis Sistem Informasi. Andi Offset, Yogyakarta.

[5] F. Tjiptono, 2014, Pemasaran Jasa. Andi Offset, Yogyakarta.

[6] F. Buttle, 2009, Customer Relationship Management: Concepts and Technologies, $2 e$, Elsevire Ltd. (Manajemen Hubungan Pelanggan). Bayumedia, Jakarta.

[7] A.S.Rosa dan M.Shalahuddin, 2013, Rekayasa Perangkat Lunak Terstruktur dan Berorientasi Objek Edisi Revisi. Informatika, Bandung.

[8] Taufiq, 2013, Sistem Informasi Manajemen Konsep Dasar, Analisis dan Metode Pengembangan. Graha Ilmu, Yogyakarta.

[9] Alexander F.K Sibero. 2013. Web Programing Power Pack.mediaKom. Yokyakarta,

[10] P. Hidayatullah, J. K. Kawistara. 2014, Pemrograman WEB. Informatika, Bandung. 